\title{
Anisotropy of ultrasonic waves propagation velocities in $\mathrm{CdHgTe} / \mathrm{CdTe}$
}

\author{
I. O. Lysiuk, V. F. Machulin, Ya. M. Olikh \\ Institute of Semiconductor Physics, NAS of Ukraine, 45, prospect Nauki, 03028 Kyiv,
}

\begin{abstract}
The complete set of elastic moduli of $\mathrm{Cd}_{0.2} \mathrm{Hg}_{0.8} \mathrm{Te}$ was obtained. Taking into account elastic moduli found for $\mathrm{Cd}_{0.2} \mathrm{Hg}_{0.8} \mathrm{Te}$ and appropriate literary data for CdTe the anisotropy of velocities of volume and Rayleigh waves propagating on (100) and (110) boundaries was calculated. Finally, peculiarities of the anisotropy of SAW propagating velocities for each of components of layered structures $\mathrm{CdHgTe} / \mathrm{CdTe}$ and for the heteroepitaxial structure as a whole were analysed.
\end{abstract}

Keywords: II-VI semiconductors, ultrasound waves, anisotropy.

Paper received 18.10.99; revised manuscript received 30.11.99; accepted for publication 17.12.99.

\section{Introduction}

Variable band-gap CdHgTe semiconductors are known to be very important for use in infrared detection devices. It is also known that they are sensitive to external influences because the essential number of linear structural defects (dislocations, low angle boundaries, blocks boundaries, etc.) and low threshold of plasticity are especial properties of this type of alloys [1]. So, CdHgTe crystals are sensitive to high-frequency intensive ultrasound influence $[2,3]$. Taking into account wide applications of investigated materials in infrared engineering when using the form of heterostructure, there is the necessity in special research of surface acoustic properties. Such data are important both for the development of acoustic methods of improving of $\mathrm{CdHgTe} / \mathrm{CdTe}$ layered structure parameters and for the development on its basis the novel acoustoelectronic devices with the acoustically controlled characteristics. So, the aim of this work was to study and compare the anisotropy of elastic properties of $\mathrm{CdTe}$ and $\mathrm{Cd}_{\mathrm{x}} \mathrm{Hg}_{1-\mathrm{x}} \mathrm{Te}(\mathrm{x}=0.2)$ semicon-ducting crystals.

\section{Experiment}

At room temperature, velocities of longitudinal $\left(V_{L}\right)$ and transverse $\left(V_{S 1}, V_{S 2}\right)$ ultrasonic waves propagating in $<110>$ and $<111>$ directions in the volume of $p-\mathrm{Cd}_{0.2} \mathrm{Hg}_{0.8} \mathrm{Te}$ samples were measured experimentally by phase-slope method $[4](f=5-15 \mathrm{MHz}$, velocity error was less than $1-2$ percents)

\section{Results and discussion}

\subsection{Anisotropy of a sound velocity of volume waves}

Taking into account elastic moduli obtained for $\mathrm{Cd}_{0.21} \mathrm{Hg}_{0.79} \mathrm{Te}$ [5] and appropriate literary data for CdTe [6] (see Table), the anisotropy of velocities of bulk and Rayleigh waves, propagating in [110] direction and on (100) and (110) boundaries, were calculated according to[6].

Results of velocity calcualtions for ultrasonic waves in $\mathrm{CdTe}$ and $\mathrm{Cd}_{0.21} \mathrm{Hg}_{0.79} \mathrm{Te}$ crystals are presented in Figs 1,2; where $V_{L}, V_{S 1}, V_{S 2}$ correspond to curves $1,2,3$ for $\mathrm{Cd}_{0.21} \mathrm{Hg}_{0.79} \mathrm{Te}$ and curves $1^{\circ}, 2^{\circ}, 3^{\circ}$ for CdTe. Let us mention that $V_{S 1}$ corresponds to the transvere wave $S 1$ with preferable polarization in the direction perpendicular to the plane of the propagation. On the contrary, polarization of the transvere wave $S 2$ with the velocity $V_{S 2}$ lies in the plane of the propagation. As one can see degeneration of transvere waves propagating along axes of the symmetry of third and fourth orders (directions $<111>$ and $<100>$ ) takes place. In general, two transvere waves with defined co-perpendicular polarization can propagate in any crystal direction.

As it is shown by our calculations (Figs $1 b, 2 b$ ), there are some directions in $\mathrm{CdTe}$ and $\mathrm{Cd}_{0.21} \mathrm{Hg}_{0.79} \mathrm{Te}$ crystals where velocities of the transverse wave are the same. For example, it occurs in the plane (100) for $V_{S 2}$ at $\varphi=22^{\circ}$; in the plane (110) for $V_{S 1}$ at $\varphi=47^{\circ}$ and for $V_{S 2}$ at $\varphi=26^{\circ}$ and $\varphi=64^{\circ}$. This fact could be used for the development of photoelectric matrix elements which use boundaries of materials, for example the heteroepitaxial $\mathrm{CdHgTe} / \mathrm{CdTe}$ ones [7]. 


\section{I.O.Lysiuk et al.: Anisotropy of ultrasonic waves propagation velocities......}
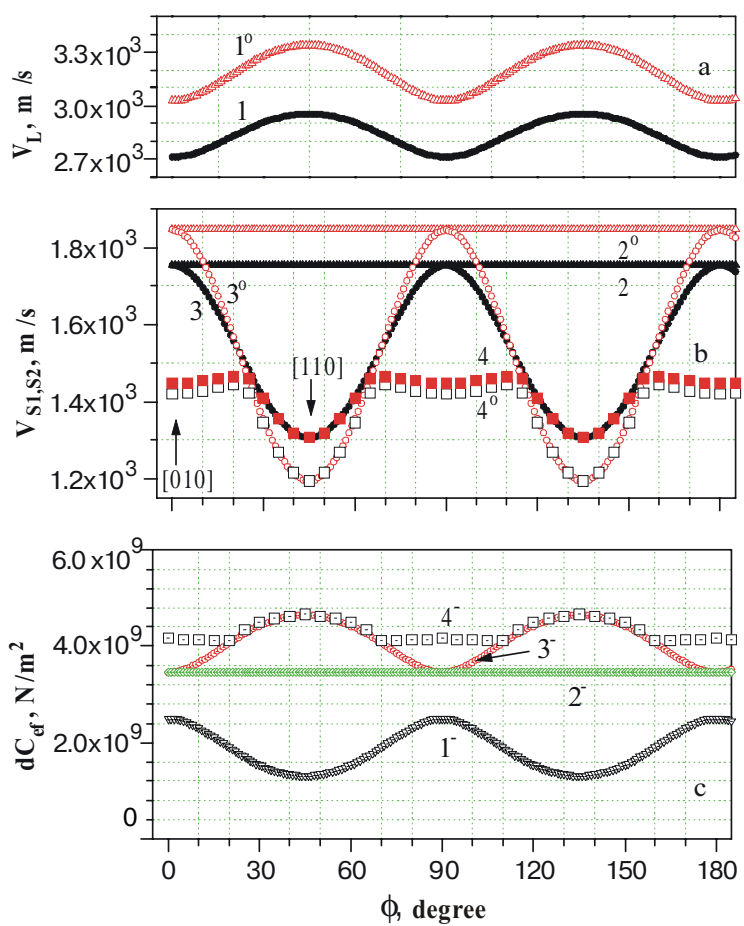

Fig. 1. Plane (100). Angle dependences of velocities $V_{L}$, longitudinal waves - curves $1,2,3$ (a); $V_{S I}$, transverse wave with perpendicular polarization to the plane $(100)-2,2^{\circ}, 2^{-} ; V_{S 2}$, transverse wave with main polarization in the plane $(100)-3,3^{\circ}, 3^{-} ; V_{R}$, - Rayleigh wave $4,4^{\circ}, 4^{-}$(b); differences of effective elastic moduli $d C_{e f}$ (c). The curves 1, 2, 3, 4 correspond to $\mathrm{Cd}_{0.21} \mathrm{Hg}_{0.79} \mathrm{Te}, 1^{\circ}, 2^{\circ}, 3^{\circ}, 4^{\mathrm{o}}-\mathrm{CdTe}, 1^{-}, 2^{-}, 3^{-}$, $4^{-}-d C_{e f}$

\subsection{Anisotropy of sound velocity of surface waves}

Taking into account possible applications of $\mathrm{CdHgTe} / \mathrm{CdTe}$ heteroepitaxial structures, it is necessary to analyze elastic properties of their boundary in detail. Such capabilities can be realized by surface acoustic wave (SAW) study. The SAW exists on a free surface of solids. These waves have a longitudinal displacement in the direction of the propagation as well as a transverse displacement in the perpendicular direction to the wave vector and the surface. Calculations of Rayleigh SAW velocities $V_{R}$ were made by numeric methods [4] using computer. Values of elastic moduli used for calculations are shown in the table.

The results of the anisotropy of $V_{R}$ in planes (100) and
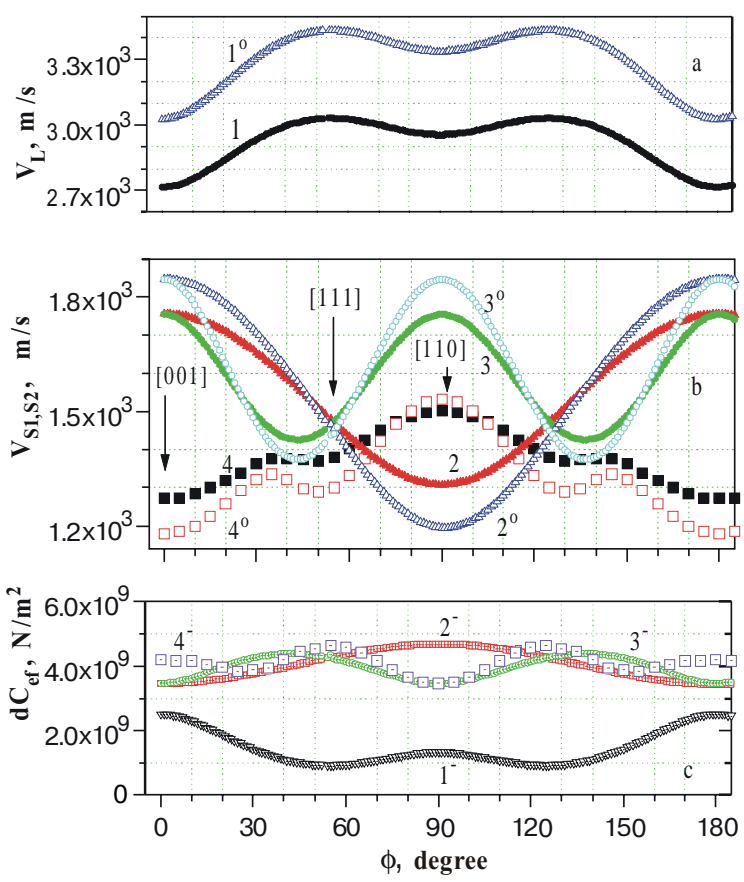

Fig. 2. Plane (110). Angle dependences of velocities $V_{L}$, longitudinal waves - curves $1,2,3$ (a); $V_{S 1}$, transverse wave with perpendicular polarization to the plane $(110)-2,2^{\circ}, 2^{-} ; V_{S 2}$, transverse wave with main polarization in the plane $(110)-3,3^{\circ}, 3^{-} ; V_{R}$, - Rayleigh wave $4,4^{\circ}, 4^{-}(\mathrm{b})$; differences of effective elastic moduli $d C_{e f}(\mathrm{c})$. The curves 1, 2, 3, 4 correspond to $\mathrm{Cd}_{0.21} \mathrm{Hg}_{0.79} \mathrm{Te}, 1^{\circ}, 2^{\circ}, 3^{\circ}, 4^{\circ}-\mathrm{CdTe}, 1^{-}, 2^{-}, 3^{-}$, $4^{-}-d C_{e f}$

(110) are given in Figs $1 \mathrm{~b}$ and 2b, respectively (curves 4, $4^{\circ}$ ). Values of $V_{R}$ for CdTe and $\mathrm{Cd}_{0.21} \mathrm{Hg}_{0.79} \mathrm{Te}$ in the plane (100) are different in any direction. But there is the special direction at $\varphi=76^{\circ}$ in the plane (110) where velocities $V_{R}$ of both materials are the same $(1480 \mathrm{~m} / \mathrm{s})$. In our opinion, this crysltallographic direction can be considered as the promi-sing one for the development of acoustical electronic devices based on $\mathrm{CdHgTe} / \mathrm{CdTe}$ heteroepitaxial structures.

\subsection{Surface elastic affinity of materials}

Comparing effective elastic moduli of certain materials of such pairs we propose a new characteristic for evaluating capability of this layered structure components - surface elastic affi-

Table. Elastic moduli $C_{i j}$, Poisson coefficient $n=C_{12} /\left(C_{11}+C_{44}\right)$ and density $\mathrm{Cd}_{\mathrm{x}} \mathrm{Hg}_{1-\mathrm{x}} \mathrm{Te}$ at $300 \mathrm{~K}$.

\begin{tabular}{cllllll}
\hline \hline \multirow{2}{*}{ Material } & \multicolumn{3}{c}{$\begin{array}{c}\text { Elastic moduli, } \\
C_{i j}, \times\end{array}$} & $\begin{array}{l}\text { Poisson } \\
\text { coefficient }\end{array}$ & $\begin{array}{l}\text { Density } \\
10^{3} \mathrm{~kg} / \mathrm{m}^{3}\end{array}$ & References \\
& $\mathrm{C}_{11}$ & $\mathrm{C}_{12}$ & $\mathrm{C}_{44}$ & $v$ & $\rho$ & \\
\hline $\mathrm{CdTe}$ & 5.351 & 3.681 & 1.994 & 0.408 & 5.86 & Our data \\
\hline$p-\mathrm{Cd}_{0.2} \mathrm{Hg}{ }_{0.8} \mathrm{Te}$ & 5.35 & 3.08 & 2.01 & 0.365 & 7.625 & {$[5]$} \\
\hline $\mathrm{Cd}_{0.21} \mathrm{Hg}{ }_{0.79} \mathrm{Te}$ & 5.6 & 3.0 & 2.34 & 0.349 & 7.603 & \\
\hline \hline
\end{tabular}




\section{I.O.Lysiuk et al.: Anisotropy of ultrasonic waves propagation velocities...}

nity of materials (SEAM). It is supposed that the SEAM describes correctly a field of elastic stresses on the boundary of these environments, too. Parameters for a quantitative evaluation of SEAM can be chosen as $d C_{e f}=d C_{R}^{S L}=$ $C_{R}^{S}-C_{R}^{L}$, where $C_{R}^{S, L}=\left(\rho^{S, L}\right)\left(V_{R}^{S, L}\right)^{2}$, and $V_{R}^{S, L}$ is the velocity of the propagation of a surface acoustic wave (the indexes $S, L$ correspond to the substrate and the layer, accordingly). This parameter can be directly obtained from real elastic stresses on the boundary. Parameter $d C_{R}^{S L}$ for Rayleigh waves and also $d C_{L}^{S L}, d C_{S 1}^{S L}, d C_{S 2}^{S L}$ for two planes (100), (110) are presented in Figs 1c,2c (curves 4- $1^{-}$, $2^{-}, 3^{-}$, accordingly). As it is shown (Figs 1c,2c), the value of $d C_{R}^{S L}$ was very close to $d C_{S 2}^{S L}$. It signifies that $d C_{S 2}^{S L}$ can be selected as approximation the SEAM parameter since calculation of angular relation of $d C_{S 2}^{S L}$ is much easier than that of $d C_{R}^{S L}$.

Respective optimum versions for structures, geometry and orientation for different pairs of substrate and layer can be easily chosen using machine calculation of the anisotropy $d C^{S, L}$. Such method of selection can pursue various purposes. For example, $d C^{S, L}$ should be minimum for heteroepitaxial structure and, on the contrary, $d C^{S, L}$ should be maximum for nanostructures.

\section{Conclusions}

On the base of results obtained for $\mathrm{CdHgTe}$ and $\mathrm{CdTe}$ monocrystals an acoustic criterion of surface elastic affinity for bordering layered structures is proposed, which, in accord with other physical reasons,sdefines the degree of mechanical stresses on the boundary of this sections.

\section{References}

1. R., Nimtz G. The properties and applications of the $\mathrm{Cd}_{\mathrm{X}} \mathrm{Hg}_{1-\mathrm{X}} \mathrm{Te}$ alloy system. // Narrow-gap semicond., 41, pp. 119-281 (1985).

2. Ya.M.Olikh. and Yu.I.Shavlyuk., Acoustostimulation of suppression of a noise in crystals $\mathrm{Cd}_{\mathrm{x}} \mathrm{Hg}_{1-\mathrm{x}} \mathrm{Te}$. // Physics of the Solid State., 38(11), pp.3365-3371 (1996).

3. A.I.Vlasenko, Ya.M.Olikh, R.K.Savkina. Acoustostimulation of activation of connected defects in rigid solutions. // Semiconductors., 33(4), pp.410-414 (1999).

4. E.Dieulesaint et D.Royer. Elastic wave in solid state. // Nauka, Moscow, (1982) 424p. (in Russian).

5. A.V.Vasilev, K.R.Kurbanov, V.N.Nikiforov et al. Eastic Properties $\mathrm{Cd}_{0.21} \mathrm{Hg}_{0.79} \mathrm{Te}$ in Temperature Interval 4-250 K. // Pis ' $m a$ v JTP., 13(11), pp.682-683 (1987).

6. Berlincourt D., Jaffe H., Shiozava L.R. Electro-elastic Properties of Sulfides, Selenides and Tellurides of Cadmium. // Phys.Rev., 129(3), pp. 1009-1017 (1963).

7. I.V.Kurylo, I.O.Rudyi, A.I.Vlasenko. Elastic properties and defects of heteroepitaxial structure $\mathrm{CdHgTe} / \mathrm{CdTe}$. // Ukr. Phys. Journal., 43(2), pp. 207-211 (1998) (in Ukrainian). 